\title{
Early Metabolic and Inflammatory Intraperitoneal Changes After Rectum Perforation
}

\author{
Ioannis Oikonomakis ${ }^{1}$, Tal M. Hörer ${ }^{2}$, Per Skoog ${ }^{3}$, Kristofer F. Nilsson², Kjell Jansson ${ }^{1}$ \\ ${ }^{1}$ Colorectal Unit, Department of General Surgery, Örebro University Hospital, Örebro; ${ }^{2}$ Department of Cardiothoracic and Vascular Surgery, \\ Faculty of Medicine and Health, Örebro University, Örebro; ${ }^{3}$ Department of Vascular Surgery and Institute of Medicine, Department of \\ Molecular and Clinical Medicine, Sahlgrenska University Hospital and Academy, Gothenburg, Sweden
}

Purpose: Anastomotic leakage (AL) is the most dreaded complication in rectal surgery. It has a great impact on postoperative morbidity and mortality. This animal model, in which we have studied postoperative metabolic and inflammatory changes, is designed to imitate an AL.

Methods: Twelve pigs were randomized into 2 groups. In the experimental group, an iatrogenic rectal perforation was performed, with the control group having a sham operation. The 2 groups were followed for 10 hours after operation with regard to vital parameters, arterial lactate, and cytokines interleukin (IL) 1, IL6, and IL10 in the blood and intraperitoneally. Intraperitoneal microdialysis analyses of glucose, lactate, glycerol, and pyruvate were performed and the lactate/pyruvate ratio was calculated.

Results: Glucose levels were lower in the experimental group after 4 hours. After 7 hours, lactate and lactate/pyruvate ratio was higher in the experimental group. At the same time intraperitoneal cytokines IL6 and IL10 were higher in the experimental group. Blood samples showed higher IL6 after 7 hours in the experimental group.

Conclusion: In this study, several significant differences between the groups in metabolic and inflammatory values were detected. Further clinical studies are recommended to evaluate the importance of intraperitoneal metabolic and inflammatory analyses as a diagnostic tool for early identification of an AL.

Keywords: Colorectal surgery; Anastomotic leak; Intraperitoneal metabolism; Intraperitoneal microdialysis; Intraperitoneal cytokines

\section{INTRODUCTION}

Anastomotic leakage (AL) is a dreaded postoperative complication and is reported frequently after rectal surgery, for example by the Swedish rectal cancer register. To decrease the fatal consequences of an anastomotic leak, such as peritonitis, sepsis, and organ failure, it has been usual to provide a diverting loop ileostomy. Using this method AL occurs in $10.3 \%$ of patients compared with

Received: Jul 8, 2019 - Revised: Sep 24, 2019 - Accepted: Sep 30, 2019

Correspondence to: Ioannis Oikonomakis, M.D.

Colorectal Unit, Department of General Surgery, Örebro University Hospital, SE-701 85 Örebro, Sweden

Tel: +46-19-6021680, Fax: +46-19-6021970

E-mail: ioannis.oikonomakis@regionorebrolan.se

ORCID: https://orcid.org/0000-0003-2789-8001

(C) 2020 The Korean Society of Coloproctology

This is an open-access article distributed under the terms of the Creative Commons Attribution NonCommercial License (https://creativecommons.org/licenses/by-nc/4.0) which permits unrestricted non-

commercial use, distribution, and reproduction in any medium, provided the original work is properly cited.
$28 \%$ of patients without a stoma [1]. Intraperitoneal microdialysis is a promising method for early detection of AL [2-5]. Intraperitoneal microdialysis studies have been presented in both animals and humans [3, 6-10]. An increasing intraperitoneal lactate/pyruvate ratio and decreasing glucose levels are signs of an increased anaerobic metabolism that may develop into splanchnic hypoxia and ischemia. Such changes have been detected prior to the appearance of postoperative complications [3, 7, 11-14]. Studies suggest intraperitoneal microdialysis as a method with potential for early detection of AL. AL is a dynamic pathophysiological process. Before systemic symptoms like fever, tachycardia, and decreased urine production become obvious, metabolic and inflammatory changes are detected intraperitoneally. Interleukin (IL) 1 and IL6 are proinflammatory cytokines that mediate inflammatory response, whereas IL10 is considered to be an antiinflammatory cytokine modulating the inflammation [15-18]. Although the usual surgical trauma also influences the levels of these cytokines, abnormal changes in the cytokines indicate the 
occurrence of inflammatory complications, including $\mathrm{AL}[4,7$, $15,17,18]$. Previous studies have suggested that monitoring cytokine levels in drain fluid or in blood samples may contribute to early detection of AL [14-18].

In this pilot study, the effects of a rectum perforation were compared between an experimental group and a control group. A rectal perforation is presumed to imitate an anastomotic leak in the experimental group. Our intention was to study the inflammatory and metabolic changes which take place in the blood and intraperitoneally during the first 10 postoperative hours.

\section{METHODS}

\section{Animals}

In this study, we used 12 healthy 3-month-old domestic pigs (a crossbreed between Swedish country breed, Hampshire and Yorkshire) of both sexes, with mean body weight of $28 \mathrm{~kg}$ (range, 21 to $37 \mathrm{~kg}$ ). The pigs were housed at room temperature at a farm, with free access to standard porcine fodder before the experiment. They were kept in a 16-hour day and 8-hour night cycle. Pigs have physiological and anatomical similarities with humans, and for this reason, they have been used in this study; but of course patients who are operated due to rectal cancer are older with comorbidity compared to young healthy pigs [19]. The experiment was approved by the regional animal ethics committee in Linköping (Dnr 174-3). The study was conducted in accordance with the guidelines of the European Union for the protection of animals used for scientific purposes. The animal experimentation in this study is reported according to the ARRIVE guidelines.

Anesthesia, fluid administration, ventilation, and euthanasia As premedication at the farm, the pigs were given azaperone (200 mg, intramuscular [IM] injection; Elanco, Herlev, Denmark). On arriving at the laboratory, anesthesia was induced by tiletamine ( 6 mg/kg, IM; Virbac, Kolding, Denmark), zolazepam (6 mg/kg, IM; Virbac), and azaperone $(4 \mathrm{mg} / \mathrm{kg}$, IM). In addition, atropine (1.5 mg, IM; Mylan, Stockholm, Sweden) was given. The experimental animals received 2 peripheral catheters $(1.1 \mathrm{~mm}$; BD Venflon Pro Safety, Helsingborg, Sweden) in auricular veins. Propofol (1 to $2 \mathrm{mg} / \mathrm{kg}$, intravenous [IV] injection; Fresenius Kabi, Uppsala, Sweden) was given if needed. The animals were orally intubated in the prone position with a 6-mm endotracheal tube (Covidien, Tullamore, Ireland). Anesthesia was maintained by propofol (10 $\mathrm{mg} / \mathrm{kg} / \mathrm{hr}, \mathrm{IV})$ and petidin $(1 \mathrm{~mL} / \mathrm{kg} / \mathrm{hr})$ applied by motorized syringe pumps (Alaris CC, Cardinal Health, Rulle, Switzerland). The depth of anesthesia was intermittently monitored by pain response. No muscle relaxants were given. Ringer acetate $(10 \mathrm{~mL} /$ $\mathrm{kg} / \mathrm{hr}$, IV; Fresenius Kabi) and 10\% glucose with $40 \mathrm{mM}$ sodium and $20 \mathrm{mM}$ potassium $(0.5 \mathrm{~mL} / \mathrm{kg} / \mathrm{hr}$, IV; Fresenius Kabi) were administrated by volume pumps (CareFusion, Alaris GP) to substitute for fluid loss. The pigs were ventilated using volume-control ventilation mode (PV 501, Breas Medical AB, Mölnlycke,
Sweden) to achieve arterial $\mathrm{pCO}_{2}$ of 5.0 to $5.3 \mathrm{kPa}$ and $\mathrm{FiO}_{2}$ was adjusted to maintain arterial $\mathrm{pO}_{2}$ at 12 to $18 \mathrm{kPa}$. The animals were covered with a thermal mattress and a forced-air warming blanket was used. At the end of the experiment, euthanasia was performed with a rapid IV injection of $40 \mathrm{mmol}$ potassium chloride (B. Braun, Danderyd, Sweden), and asystole and circulatory arrest were confirmed with electrocardiogram and blood pressure recordings.

\section{Surgical preparation and measurements}

A 4-Fr introducer was placed in the right carotid artery for the measurement of systemic blood pressure as well as blood sampling. The blood samples were analyzed for blood gases, white blood cells (WBC), C-reactive protein (CRP), and cytokines. A midline abdominal incision was performed. A 14-Fr Foley catheter was inserted in the urinary bladder and fixed with a pursestring suture. A free-floating microdialysis catheter was placed intraperitoneally in the left lower quadrant, between intestinal loops. A syringe pump was used to propel a solution. The microdialysate was analyzed for glucose, glycerol, pyruvate, lactate, and glycerol, and the lactate/pyruvate ratio was calculated. An intraperitoneal drain was placed via the midline incision to collect intra-abdominal fluid, which was analyzed for cytokine concentrations. Rectal perforation was performed in the animals in the experimental group with a Metzenbaum scissor. The perforation was located 8 $\mathrm{cm}$ orally of the anal verge. The diameter of the hole was $3 \mathrm{~cm}$. The midline incision was sutured at the end of the procedure with a continuous suture.

\section{Protocol}

The animals were blindly randomized before the operation into 2 groups-an experimental group with rectal perforation and a sham-operated control group-using an envelope system 1:1. After the operation, there was an intervention-free period of 1 hour. Blood pressure, pulse, temperature, and urine production were measured 1, 4, 7, and 10 hours after the procedure. At the same times intraperitoneal and blood samples were collected and analyzed. Blood samples were collected from the carotid artery and were analyzed for blood gases, WBC, CRP, and cytokines IL1, IL6, and IL10. Intraperitoneal fluid was collected via the intra-abdominal drain to be analyzed afterward for cytokines IL1, IL6, and IL10. Microdialysis samples were collected and analyzed immediately bedside (Fig. 1).

\section{Intraperitoneal microdialysis}

Intraperitoneal microdialysis is a method that uses a double lumen catheter with diameter of $0.9 \mathrm{~mm}$ placed between the small intestine loops free-floating. In this study, microdialysis equipment from M-dialysis AB (Stockholm, Sweden) has been used. At the end of this catheter, there is a semipermeable membrane. The membrane pores are of 2 different sizes: $20 \mathrm{kDa}$ pores allow lactate, pyruvate, glucose, and glycerol to get through the membrane; and $100 \mathrm{kDa}$ 


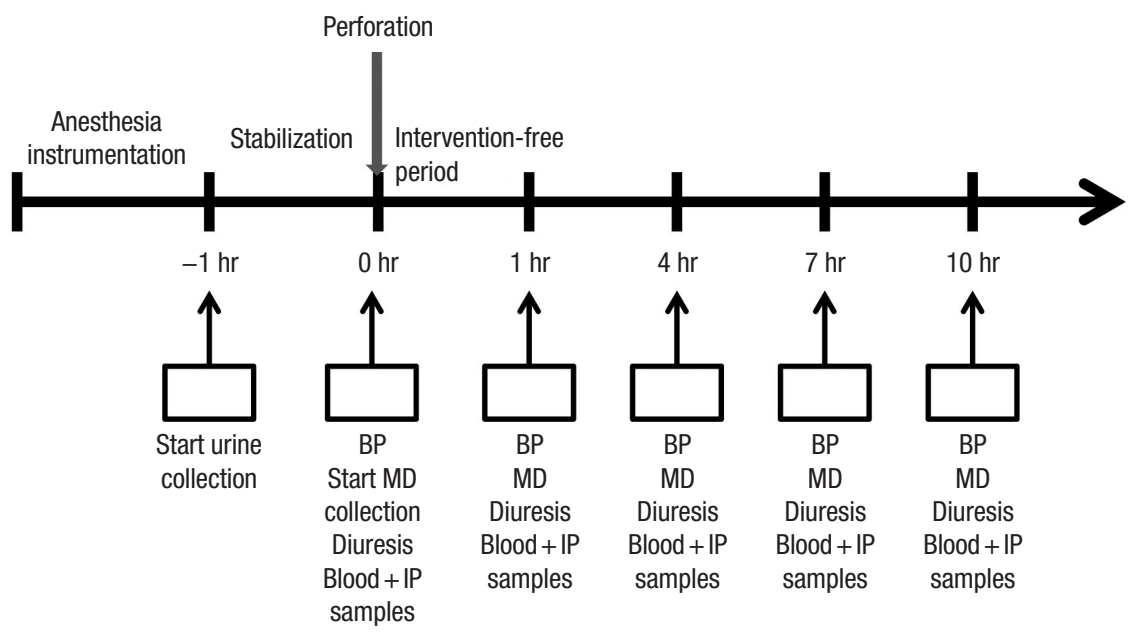

Fig. 1. Experiment protocol. MD, microdialysis; BP, blood pressure; IP, intraperitoneal.

pores which also allow larger particles such as cytokines through. A microdialysis pump provides a constant flow to the semipermeable membrane, which facilitates the equilibrium of ringer dialysate with the extracellular tissue. This sample is collected in a microvial. The microvial is analyzed by a computer run spectrophotometer. The analysis can be performed continuously with 20 minutes intervals between the sampling, time that is needed for the microvial to be filled with an adequate amount of fluid. The analysis of lactate, pyruvate, glucose, and glycerol takes 7 minutes, which basically allows continuous monitoring of the balance between aerobic and anaerobic metabolism at the cellular level.

\section{Cytokine measurements}

Serum and intraperitoneal concentrations of IL1, IL6, and IL10 were simultaneously determined using a porcine cytokine/chemokine magnetic bead MILLIPLEX ${ }^{\circledR}$ MAP kit (EMD Millipore Corp., Billerica, MA, USA). After an initial centrifugation of the samples $(14,000 \times g, 10$ minutes $)$, the assay was performed according to the manufacturer's protocol. The serial diluted standard curves ranged between $0.122-500 \mathrm{ng} / \mathrm{mL}$ for IL1 and $0.024-$ $100 \mathrm{ng} / \mathrm{mL}$ for IL6 and IL10. Measurements and analyses were performed using a Luminex 200 (Luminex Corp., Austin, TX, USA) and xPONENT software ver. 3.1 (Luminex).

\section{Statistical analysis}

Data are presented as median and interquartile range. In the statistical analysis, pairwise comparisons between groups were performed after 1, 4, 7, and 10 hours using Wilcoxon rank sum test (Statistix 8, Analytical Software, Tallahassee, FL, USA). A P-value less than 0.05 was regarded as statistically significant.

\section{RESULTS}

\section{Animal inclusion}

Of the 13 animals used in this study, 1 animal randomized to the control group was excluded due to intestinal ischemia. The remaining 12 animals (6 control and 6 experimental animals) were stable in vital and laboratory parameters during the interventionfree period of 1 hour.

\section{Vital parameters}

Pulse: Preoperatively both groups started at around 110 beats/min and remained stable during the study.

Blood pressure: Preoperatively both groups started with a systolic blood pressure around $100 \mathrm{mmHg}$ and remained stable during study.

Urine production: The experimental group produced $15-\mathrm{mL}$ urine during the first hour of the study. Diuresis increased during the next 7 postoperative hours to a peak of $243 \mathrm{~mL} / \mathrm{hr}$, thereafter decreasing to $149 \mathrm{~mL} / \mathrm{hr}$. The control group produced $25 \mathrm{~mL}$ during the first hour, then increased to a stable value of $109 \mathrm{~mL} / \mathrm{hr}$ during the rest of the study.

\section{Arterial blood samples}

$W B C$

The experimental group started at $21.8 \times 10^{9} / \mathrm{L}$, which rapidly decreased to $13.1 \times 10^{9} / \mathrm{L} 1$ hour later, then increased slightly to $15.8 \times 10^{9} / \mathrm{L}$ at the 4 th hour postoperatively, and was $12.2 \times 10^{9} / \mathrm{L}$ at the end of the study. The control group started at $15.8 \times 10^{9} / \mathrm{L}$, increased slightly to $18.5 \times 10^{9} / \mathrm{L}$ and remained stable at this value during the rest of the study. A significant difference was detected preoperatively between the groups $(\mathrm{P}=0.045)$ (Table 1$)$.

\section{CRP}

In both groups, CRP levels were $1 \mathrm{mg} / \mathrm{L}$ preoperatively and remained the same during the study. No significant difference was detected (Table 1).

\section{Lactate}

The experimental group started at $1.79 \mathrm{mmol} / \mathrm{L}$, increased during 
Table 1. Blood and intraperitoneal values during the experiment

\begin{tabular}{|c|c|c|c|c|c|c|}
\hline \multirow{2}{*}{ Sample } & & \multirow{2}{*}{ Preoperative } & \multicolumn{4}{|c|}{ Postoperative time (hr) } \\
\hline & & & 1 & 4 & 7 & 10 \\
\hline \multicolumn{7}{|l|}{ Blood } \\
\hline \multirow[t]{3}{*}{ WBC $\left(\times 10^{9} / L\right)$} & Exp & $21.8(18.1-25.6)$ & $13.1(10.8-16.9)$ & $15.8(10.7-24.0)$ & $13.4(22.6-18.5)$ & $12.2(8.97-16.0)$ \\
\hline & Cont & $15.9(13.1-17.9)$ & $18.5(7.8-25.2)$ & $17.8(14.7-22.8)$ & $18.5(11.6-22.1)$ & $18.6(8.56-24.6)$ \\
\hline & P-value & $0.045^{\mathrm{a}}$ & 0.575 & 0.936 & 0.648 & 0.312 \\
\hline \multirow[t]{3}{*}{$\mathrm{CRP}(\mathrm{mg} / \mathrm{L})$} & Exp & 1 & 1 & 1 & 1 & 1 \\
\hline & Cont & 1 & 1 & 1 & 1 & 1 \\
\hline & P-value & NS & NS & NS & NS & NS \\
\hline \multirow[t]{3}{*}{ IL1 ( $\mu \mathrm{g} / \mathrm{L})$} & Exp & $0.12(0.06-0.27)$ & $0.12(0.06-0.26)$ & $0.20(0.12-0.54)$ & $0.44(0.21-0.6)$ & $0.61(0.38-0.95)$ \\
\hline & Cont & $0.09(0.08-0.40)$ & $0.07(0.06-0.38)$ & $0.18(0.09-0.42)$ & $0.19(0.09-0.65)$ & $0.31(0.09-0.95)$ \\
\hline & P-value & 0.936 & 0.514 & 0.574 & 0.378 & 0.379 \\
\hline \multirow[t]{3}{*}{ IL6 ( $\mu \mathrm{g} / \mathrm{L})$} & Exp & $0.02(0.02-0.02)$ & $0.04(0.01-0.06)$ & $0.44(0.14-0.74)$ & $0.45(0.16-0.66)$ & $0.43(0.21-1.12)$ \\
\hline & Cont & $0.02(0.01-0.13)$ & $0.02(0.01-0.14)$ & $0.07(0.02-0.18)$ & $0.065(0.02-0.43)$ & $0.065(0.02-0.40)$ \\
\hline & P-value & 0.850 & 0.627 & $0.020^{\mathrm{a}}$ & 0.065 & 0.066 \\
\hline \multirow[t]{3}{*}{ IL10 ( $\mu \mathrm{g} / \mathrm{L})$} & Exp & $0.045(0.02-0.22)$ & $0.045(0.03-0.22)$ & $0.07(0.04-0.20)$ & $0.09(0.02-0.19)$ & $0.095(0.05-0.2)$ \\
\hline & Cont & $0.045(0.01-0.37)$ & $0.05(0.03-0.65)$ & $0.06(0.04-0.38)$ & $0.055(0.03-0.36)$ & $0.1(0.05-0.57)$ \\
\hline & P-value & 0.810 & 0.926 & 0.745 & 0.747 & 0.927 \\
\hline \multirow[t]{3}{*}{ a-Lactate $(\mathrm{mmol} / \mathrm{L})$} & Exp & 1.79 (1.39-2.63) & $1.96(1.80-3.49)$ & $1.30(1.15-1.50)$ & $0.88(0.73-1.30)$ & $0.80(0.59-0.84)$ \\
\hline & Cont & $2.37(1.92-4.10)$ & $2.07(1.85-4.67)$ & $1.66(1.35-1.97)$ & $1.02(0.74-1.33)$ & $1.00(0.81-1.19)$ \\
\hline & P-value & 0.297 & 0.630 & 0.128 & 0.689 & $0.045^{\mathrm{a}}$ \\
\hline \multicolumn{7}{|l|}{ Intraperitoneal } \\
\hline \multirow[t]{3}{*}{ Glucose (mmol/L) } & Exp & & $1.84(0.27-4.18)$ & $0.74(0.25-1.37)$ & $0.95(0.05-2.12)$ & $1.76(0.08-1.96)$ \\
\hline & Cont & & $4.55(2.13-6.15)$ & $4.39(2.28-5.37)$ & $3.57(1.70-3.84)$ & $3.37(1.91-4.13)$ \\
\hline & P-value & & 0.128 & $0.014^{\mathrm{a}}$ & 0.052 & 0.07 \\
\hline \multirow[t]{3}{*}{ Lactate (mmol/L) } & Exp & & $5.24(4.79-6.85)$ & $6.50(4.40-8.35)$ & $8.19(4.14-10.60)$ & $6.26(3.88-8.93)$ \\
\hline & Cont & & $5.7(2.04-11.03)$ & $4.52(2.86-5.88)$ & $2.36(1.33-4.00)$ & $2.06(1.46-2.96)$ \\
\hline & P-value & & 0.936 & 0.229 & $0.031^{\mathrm{a}}$ & 0.093 \\
\hline \multirow[t]{3}{*}{ L/P ratio } & Exp & & 17.2 (14.6-28.2) & $25.8(14.8-30.6)$ & $31(18.6-45.2)$ & $23.4(16.7-71.7)$ \\
\hline & Cont & & $15.8(10.8-21.6)$ & $16.3(13.4-17.4)$ & $12.0(10.0-15.7)$ & $11.8(8.5-18.6)$ \\
\hline & $P$-value & & 0.471 & 0.174 & $0.008^{\mathrm{a}}$ & $0.036^{\mathrm{a}}$ \\
\hline \multirow[t]{3}{*}{ Glycerol (g/mol) } & Exp & & $49.6(16.1-93.8)$ & $35.8(20.2-48.1)$ & $26.0(19.4-34.7)$ & $17.5(9.3-38.1)$ \\
\hline & Cont & & $76.9(55.9-140.0)$ & $44.8(34.1-100.0)$ & $32.6(26.5-45.5)$ & $29.2(13.9-67.6)$ \\
\hline & P-value & & 0.298 & 0.298 & 0.230 & 0.471 \\
\hline \multirow[t]{3}{*}{$\| \mathrm{L} 1(\mu \mathrm{g} / \mathrm{L})$} & Exp & & $4.8(2.1-10.3)$ & $38.0(11.5-71.6)$ & $81.6(48.0-128.2)$ & $94.0(68.0-143.5)$ \\
\hline & Cont & & $23.0(3.1-41.1)$ & $46.0(30.4-70.5)$ & $52.5(38.6-83.5)$ & $52.7(43.5-147.0)$ \\
\hline & $\mathrm{P}$-value & & 0.230 & 0.810 & 0.298 & 0.320 \\
\hline \multirow[t]{3}{*}{ IL6 ( $\mu \mathrm{g} / \mathrm{L})$} & Exp & & $2.9(0.8-3.6)$ & $9.4(2.9-14.8)$ & $17.8(13.1-20.4)$ & $18.9(17.1-22.6)$ \\
\hline & Cont & & $3.2(0.09-9.95)$ & $9.6(5.7-12.0)$ & $11.5(8.8-14.7)$ & $10.2(6.3-15.4)$ \\
\hline & $P$-value & & 0.936 & 0.689 & 0.066 & $0.045^{\mathrm{a}}$ \\
\hline \multirow[t]{3}{*}{ IL10 ( $\mu \mathrm{g} / \mathrm{L})$} & Exp & & $0.27(0.15-0.44)$ & $0.52(0.21-1.42)$ & $1.00(0.77-1.76)$ & $1.74(0.86-2.16)$ \\
\hline & Cont & & $0.14(0.10-0.46)$ & $0.28(0.14-0.64)$ & $0.52(0.32-1.04)$ & $0.55(0.30-1.36)$ \\
\hline & P-value & & 0.148 & 0.575 & 0.093 & $0.045^{\mathrm{a}}$ \\
\hline
\end{tabular}

Values are presented as median (interquartile range) if otherwise specified.

Exp, experience group; Cont, control group; WBC, white blood cell; CRP, C-reactive protein; IL, interleukin; a-Lactate, arterial lactate; L/P, lactate/pyruvate; NS, not significant.

aSignificant differences. 
the first hour to $1.96 \mathrm{mmol} / \mathrm{L}$, and then decreased to $0.78 \mathrm{mmol} / \mathrm{L}$ at the end of the study. The control group started at $2.37 \mathrm{mmol} / \mathrm{L}$ and decreased steadily during the study to $1.00 \mathrm{mmol} / \mathrm{L}$ at the end. A significant difference was detected 10 hours postoperatively $(\mathrm{P}=0.045)$ (Table 1, Fig. 2).

\section{IL1}

The experimental group started at $0.12 \mu \mathrm{g} / \mathrm{L}$ and increased steadily during the study, reaching a peak value of $0.60 \mu \mathrm{g} / \mathrm{L}$ at the end of the experiment. The control group started at $0.09 \mu \mathrm{g} / \mathrm{L}$ and increased steadily during the study, reaching a peak value of 0.31 $\mu \mathrm{g} / \mathrm{L}$ at the end of the experiment. No significant differences were found between the groups (Table 1).

\section{IL6}

The experimental group started at $0.02 \mu \mathrm{g} / \mathrm{L}$, increased rapidly during the first 4 hours to $0.44 \mu \mathrm{g} / \mathrm{L}$, and then remained stable. The control group started at $0.02 \mu \mathrm{g} / \mathrm{L}$, increased slightly to reach a peak value of $0.07 \mu \mathrm{g} / \mathrm{L} 4$ hours later, and then remained stable. A significant difference between the groups was found 4 hours after the perforation ( $\mathrm{P}=0.02)$ (Table 1, Fig. 2).

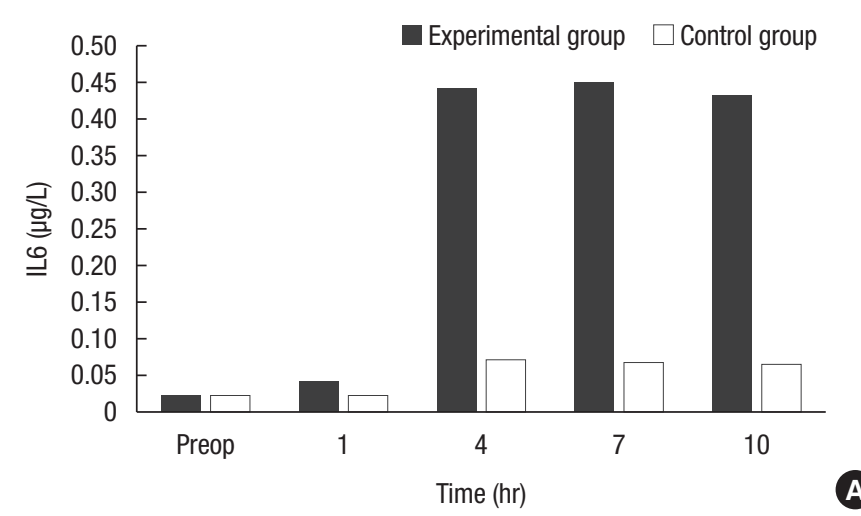

\section{IL10}

The experimental group started at $0.045 \mu \mathrm{g} / \mathrm{L}$ and reached a value of $0.095 \mu \mathrm{g} / \mathrm{L}$ at the end of the experiment. The control group started at $0.05 \mu \mathrm{g} / \mathrm{L}$ and increased slightly during the study to reach a peak value of $0.1 \mu \mathrm{g} / \mathrm{L}$ at the end of the experiment. No significant differences were detected (Table 1).

\section{Intraperitoneal cytokines \\ IL1}

The experimental group started at $4.83 \mu \mathrm{g} / \mathrm{L}$ and increased rapidly to $94.0 \mu \mathrm{g} / \mathrm{L}$ at the end of the experiment. The control group started at $23.0 \mu \mathrm{g} / \mathrm{L}$, increased to $52.5 \mu \mathrm{g} / \mathrm{L} 7$ hours postoperatively, and then remained stable. No significant differences were found (Table 1).

\section{IL6}

The experimental group started at $2.86 \mu \mathrm{g} / \mathrm{L}$ and increased rapidly during the study to reach a peak value of $18.9 \mu \mathrm{g} / \mathrm{L}$ at the end of the experiment. The control group started at $3.16 \mu \mathrm{g} / \mathrm{L}$, increased to $11.5 \mu \mathrm{g} / \mathrm{L}$ after 7 hours, and then decreased to $10.2 \mu \mathrm{g} / \mathrm{L}$ at the end of the study. A significant difference was detected 10 hours postoperatively $(\mathrm{P}=0.0453)$ (Table 1, Fig. 3).

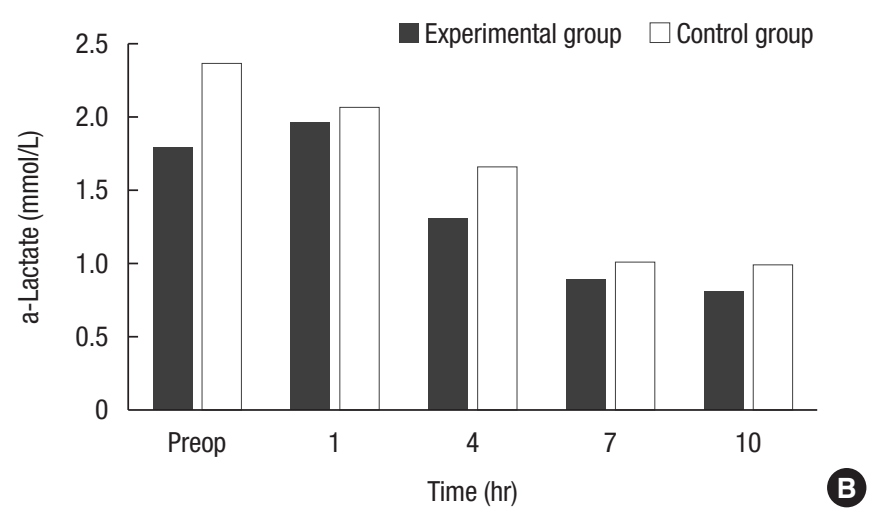

Fig. 2. (A) Blood interleukin 6 (IL6) levels. (B) Arterial lactate (a-lactate) levels. Preop, preoperative.
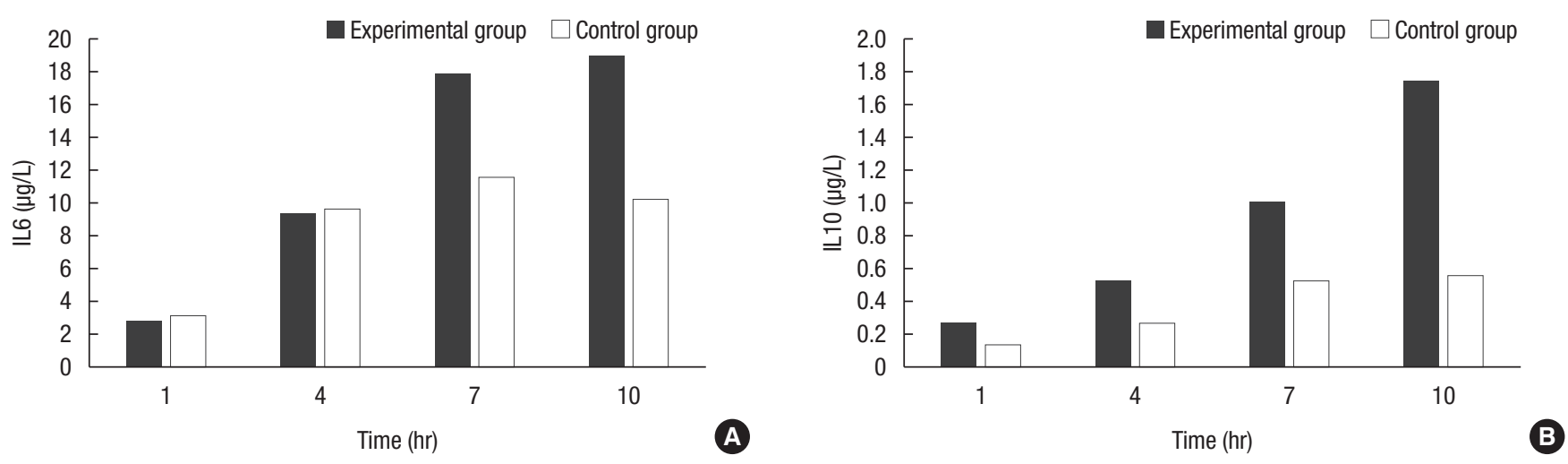

Fig. 3. (A) Intraperitoneal interleukin (IL) 6. (B) Intraperitoneal IL10. Curves show median values. 


\section{IL10}

The experimental group started at $0.265 \mu \mathrm{g} / \mathrm{L}$ and increased steadily to reach a peak value of $1.74 \mu \mathrm{g} / \mathrm{L}$ at the end of the experiment. The control group started at a level of $0.135 \mu \mathrm{g} / \mathrm{L}$ and increased steadily to reach a peak value of $0.55 \mu \mathrm{g} / \mathrm{L}$ at the end of the study. The experimental group had a significantly higher value of 10 hours postoperatively $(\mathrm{P}=0.0453)$ (Table 1, Fig. 3).
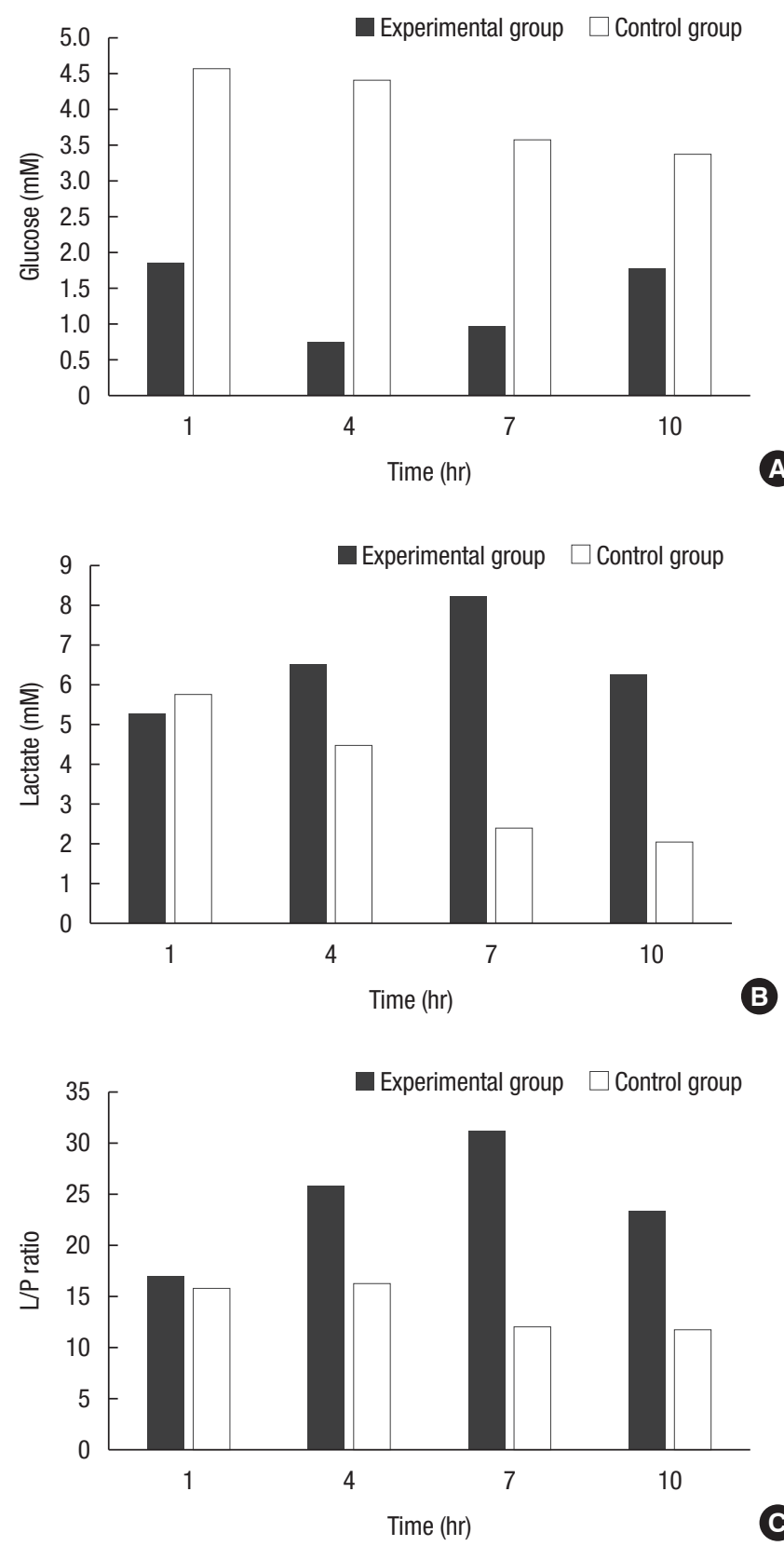

Fig. 4. Microdialysis samples from a free-floating catheter. (A) Intraperitoneal glucose. (B) Intraperitoneal lactate. (C) Intraperitoneal lactate/pyruvate $(\mathrm{L} / \mathrm{P})$ ratio. Curves show median values.

\section{Intraperitoneal microdialysis Glucose}

The experimental group started at a level of $1.84 \mathrm{mM}$, which decreased steadily to $0.74 \mathrm{mM} 1$ hour postoperatively and then increased to a value of $1.76 \mathrm{mM}$ at the end of the experiment. The control group started at $4.55 \mathrm{mM}$ and decreased steadily to reach a value of $3.37 \mathrm{mM}$ at the end of the study. The glucose value in the experimental group was significantly lower 4 hours postoperatively $(\mathrm{P}=0.0137)$ (Table 1, Fig. 4).

\section{Lactate}

The experimental group started at $5.24 \mathrm{mM}$ and increased steadily during the study to reach a peak value of $8.19 \mathrm{mM} 7$ hours postoperatively, and then decreased slightly to $6.26 \mathrm{mM}$ at the end of the experiment. The control group started at $5.7 \mathrm{mM}$, which steadily decreased during the study, to reach its lowest value of $2.06 \mathrm{mM}$ at the end of the study. Lactate values in the experimental group were significantly higher than in the control group 7 hours postoperatively $(\mathrm{P}=0.0306)$ (Table 1, Fig. 4).

\section{Lactate/pyruvate ratio}

The experimental group started at 17.2 and increased steadily to reach a peak value of 31,7 hours postoperatively, and then decreased to 23.4 at the end of the experiment. The control group started at 15.8 and decreased to reach the lowest value of 11.8 at the end of the study. Significantly higher lactate/pyruvate ratios were detected in the experimental group 7 hours $(P=0.008)$ and 10 hours $(\mathrm{P}=0.036)$ after the perforation (Table 1, Fig. 4).

\section{Glycerol}

The experimental group started at $49.6 \mathrm{mM}$, decreased during the first 4 hours of the study to $35.8 \mathrm{mM}$, and then decreased steadily to $29.2 \mathrm{mM}$ at the end of the experiment. The control group started at $76.9 \mathrm{mM}$ and decreased steadily during the study, to reach the lowest value of $29.2 \mathrm{mM}$ at the end of the experiment. No significant differences were detected between the groups (Table 1).

\section{DISCUSSION}

$\mathrm{AL}$ is the most serious complication after colorectal surgery. It leads to high morbidity and can increase mortality, but is unfortunately difficult to detect. The etiology of the leakage may be multifactorial; ischemia of the intestine at the suture line, the presence of local infection, tension at the anastomosis, low height of the anastomosis, and suboptimal surgical technique can be some of the main causes. Age, male sex, coexisting diseases, smoking, and chemoradiotherapy treatment before the operation are wellknown risk factors [20-25]. A variety of methods have been used to identify early AL $[6,7,13,15,26]$. Early detection of AL by microdialysis is promising according to previous studies $[6,7,13,26$, 27]. All these clinical studies followed the patients after the operation without the knowledge of the specific time of the rectum 
perforation. In our study, the AL is imitated by a rectal perforation. Knowing the exact time of the perforation makes it is easier to follow up the consequences. The changes in intraperitoneal metabolism and inflammation, which are mediated by intraperitoneal and IV cytokines, are a reflection of this rapid dynamic pathophysiological process.

When analyzing metabolism with microdialysis, measurements are performed extracellularly in the peritoneal fluid close to the cells and capillaries. The glucose is delivered to the cells via the capillaries and the intracellular uptake of glucose is regulated by insulin. Glucose is metabolized to pyruvate. Pyruvate is then converted to lactate if the supply of oxygen is insufficient (anaerobic reaction), but in the presence of oxygen (aerobic reaction) pyruvate is converted to acetyl-CoA, and in the mitochondria further reactions in the tricarboxylic acid cycle take place, leading to more effective energy utilization. The ratio between lactate and pyruvate describes the current relationship between aerobic and anaerobic utilization, and it is more the trend of the curve over time rather than the individual values that best describes the current metabolism. Intraperitoneal glucose was significantly lower in the experimental group 4 hours after the perforation $(\mathrm{P}=$ $0.0137)$ and it continues to be lower in comparison with the control group during the whole study. The lower level of glucose in the experimental group could be explained by higher glycolysis, ischemia, or higher consumption which occur in sepsis. Intraperitoneal lactate was higher in the experimental group already one hour after the operation and differed significantly 7 hours after perforation $(\mathrm{P}=0.036)$. The difference was no longer significant 10 hours after the perforation, but the small size of the study can be the reason for it not reaching significant values. Nevertheless, the lactate/ pyruvate ratio was significantly higher in the experimental group at both 7 and 10 hours after the perforation. Higher levels of lactate and lactate/pyruvate ratio in the experimental group indicate increased anaerobic metabolism due to inflammatory process that occurs after the rectal perforation. This hypothesis is also supported by the fact that inflammatory cytokines are higher in the experimental group. Intraperitoneal IL1 was twice as high in the experimental group at both 7 and 10 hours postoperatively, but no statistically significant differences were seen. Intraperitoneal IL6 differed significantly between the groups at 10 hours $(\mathrm{P}=0.0453)$. IL10, which is an anti-inflammatory cytokine, also reached significantly higher levels 10 hours after the operation $(\mathrm{P}=0.0453)$ in the experimental group.

There is an ongoing discussion about cutoff values in lactate and lactate/pyruvate ratio. Lactate values over 4 (and 5) $\mathrm{mmol} / \mathrm{L}$, lactate/pyruvate ratio over 20 , have been suggested as pathological but the trend of values over time seems to be more important than individual values when interpreting intraperitoneal microdialysis $[3,27]$.

Blood IL6 levels were significantly higher in the experimental group already 4 hours, indicating an early systemic inflammatory response after rectal perforation $(\mathrm{P}=0.02)$ after the operation.
Studies in CRP and procalcitonin have shown interesting data but the response after anastomotic leak will appear later than the IL6 response. Intraperitoneal cytokine levels were higher than the blood, suggesting a higher inflammation in the abdominal cavity $[4,28]$.

WBC was significantly higher in the experimental group preoperatively but no other preoperative laboratory or clinical differences between the groups were seen. Thus, the 2 study groups were very similar before the operation. This finding indicates that higher arterial lactate levels in the control group were seen 10 hours after the operation, but are within physiological limits. Such small differences in the individual analyses are probably due to the small size of the study.

In conclusion, intraperitoneal metabolism measured by microdialysis with analyses of lactate and lactate/pyruvate ratio and intraperitoneal inflammation measured by cytokines IL6 and IL10 showed early differences between the experimental and control groups. Intraperitoneal lactate was more sensitive than arterial lactate. IL6 was the most sensitive cytokine, both intraperitoneally and in the blood, for the early detection of the rectal perforation. Repeated blood analysis of IL6 seems also promising for early detection of AL. Further clinical studies should be done to evaluate these methods for early detection of AL.

\section{CONFLICT OF INTEREST}

No potential conflict of interest relevant to this article was reported.

\section{ACKNOWLEDGMENTS}

Funding was from the Research Committee of Region Örebro County and Nyckelfonden at Örebro University Hospital (OLL408401) and Örebro County (OLL-553041). The authors appreciate Peter Nicol for scientific and language support.

\section{REFERENCES}

1. Matthiessen P, Hallböök O, Rutegård J, Simert G, Sjödahl R. Defunctioning stoma reduces symptomatic anastomotic leakage after low anterior resection of the rectum for cancer: a randomized multicenter trial. Ann Surg 2007;246:207-14.

2. Jansson K, Jonsson T, Norgren L. Intraperitoneal microdialysis: a new method to monitor patients after abdominal surgery. Int J Intensive Care 2003;10:8-13.

3. Jansson K, Ungerstedt J, Jonsson T, Redler B, Andersson M, Ungerstedt $\mathrm{U}$, et al. Human intraperitoneal microdialysis: increased lactate/pyruvate ratio suggests early visceral ischaemia. A pilot study. Scand J Gastroenterol 2003;38:1007-11.

4. Matthiessen P, Strand I, Jansson K, Törnquist C, Andersson M, Rutegård J, et al. Is early detection of anastomotic leakage possible by intraperitoneal microdialysis and intraperitoneal cytokines af- 
ter anterior resection of the rectum for cancer? Dis Colon Rectum 2007;50:1918-27.

5. Ellebæk M, Qvist N, Fristrup C, Mortensen MB. Mediastinal microdialysis in the diagnosis of early anastomotic leakage after resection for cancer of the esophagus and gastroesophageal junction. Am J Surg 2014;208:397-405.

6. Ellebaek Pedersen M, Qvist N, Bisgaard C, Kelly U, Bernhard A, Møller Pedersen S. Peritoneal microdialysis. Early diagnosis of anastomotic leakage after low anterior resection for rectosigmoid cancer. Scand J Surg 2009;98:148-54.

7. Jansson K, Redler B, Truedsson L, Magnuson A, Ungerstedt U, Norgren L. Postoperative on-line monitoring with intraperitoneal microdialysis is a sensitive clinical method for measuring increased anaerobic metabolism that correlates to the cytokine response. Scand J Gastroenterol 2004;39:434-9.

8. Hörer TM, Skoog P, Nilsson KF, Oikonomakis I, Larzon T, Norgren L, et al. Intraperitoneal metabolic consequences of supraceliac aortic balloon occlusion in an experimental animal study using microdialysis. Ann Vasc Surg 2014;28:1286-95.

9. Skoog P, Hörer T, Nilsson KF, Agren G, Norgren L, Jansson K. Intra-abdominal hypertension--an experimental study of early effects on intra-abdominal metabolism. Ann Vasc Surg 2015;29: 128-37.

10. Skoog P, Hörer TM, Nilsson KF, Norgren L, Larzon T, Jansson K. Abdominal hypertension and decompression: the effect on peritoneal metabolism in an experimental porcine study. Eur J Vasc Endovasc Surg 2014;47:402-10.

11. Grotz M, Regel G, Bastian L, Weimann A, Neuhoff K, Stalp M, et al. The intestine as the central organ in the development of multiple organ failure after severe trauma: pathophysiology and therapeutic approaches. Zentralbl Chir 1998;123:205-17.

12. Hörer T, Norgren L, Jansson K. Complications but not obesity or diabetes mellitus have impact on the intraperitoneal lactate/pyruvate ratio measured by microdialysis. Scand J Gastroenterol 2010; 45:115-21.

13. Hörer TM, Norgren L, Jansson K. Intraperitoneal glycerol levels and lactate/pyruvate ratio: early markers of postoperative complications. Scand J Gastroenterol 2011;46:913-9.

14. Jansson K, Jansson M, Andersson M, Magnuson A, Ungerstedt U, Norgren L. Normal values and differences between intraperitoneal and subcutaneous microdialysis in patients after non-complicated gastrointestinal surgery. Scand J Clin Lab Invest 2005;65: 273-81.

15. Sammour T, Singh PP, Zargar-Shoshtari K, Su’a B, Hill AG. Peritoneal cytokine levels can predict anastomotic leak on the first postoperative day. Dis Colon Rectum 2016;59:551-6.

16. Sparreboom CL, Wu Z, Dereci A, Boersema GS, Menon AG, Ji J, et al. Cytokines as early markers of colorectal anastomotic leak- age: a systematic review and meta-analysis. Gastroenterol Res Pract 2016;2016:3786418.

17. van Berge Henegouwen MI, van der Poll T, van Deventer SJ, Gouma DJ. Peritoneal cytokine release after elective gastrointestinal surgery and postoperative complications. Am J Surg 1998;175: 311-6.

18. Yamamoto T, Umegae S, Matsumoto K, Saniabadi AR. Peritoneal cytokines as early markers of peritonitis following surgery for colorectal carcinoma: a prospective study. Cytokine 2011;53:23942.

19. Yeom SC, Cho SY, Park CG, Lee WJ. Analysis of reference interval and age-related changes in serum biochemistry and hematology in the specific pathogen free miniature pig. Lab Anim Res 2012;28:245-53.

20. Rencuzogullari A, Benlice C, Valente M, Abbas MA, Remzi FH, Gorgun E. Predictors of anastomotic leak in elderly patients after colectomy: nomogram-based assessment from the american college of surgeons national surgical quality program procedure-targeted cohort. Dis Colon Rectum 2017;60:527-36.

21. Daams F, Wu Z, Lahaye MJ, Jeekel J, Lange JF. Prediction and diagnosis of colorectal anastomotic leakage: a systematic review of literature. World J Gastrointest Surg 2014;6:14-26.

22. Dekker JW, Liefers GJ, de Mol van Otterloo JC, Putter H, Tollenaar RA. Predicting the risk of anastomotic leakage in left-sided colorectal surgery using a colon leakage score. J Surg Res 2011; 166:e27-34.

23. Hayden DM, Mora Pinzon MC, Francescatti AB, Saclarides TJ. Patient factors may predict anastomotic complications after rectal cancer surgery: anastomotic complications in rectal cancer. Ann Med Surg (Lond) 2014;4:11-6.

24. Hu MH, Huang RK, Zhao RS, Yang KL, Wang H. Does neoadjuvant therapy increase the incidence of anastomotic leakage after anterior resection for mid and low rectal cancer? A systematic review and meta-analysis. Colorectal Dis 2017;19:16-26.

25. Ott K, Heger U. Are there gender-specific differences in complications following abdominal surgery?. Zentralbl Chir 2015;140: 273-8.

26. Daams F, Wu Z, Cakir H, Karsten TM, Lange JF. Identification of anastomotic leakage after colorectal surgery using microdialysis of the peritoneal cavity. Tech Coloproctol 2014;18:65-71.

27. Ellebæk MB, Daams F, Jansson K, Matthiessen P, Cosse C, Fristrup $\mathrm{C}$, et al. Peritoneal microdialysis as a tool for detecting anastomotic leakage in patients after left-side colon and rectal resection: a systematic review. Scand J Gastroenterol 2018;53:1625-32.

28. Hayati F, Mohd Azman ZA, Nasuruddin DN, Mazlan L, Zakaria $\mathrm{AD}$, Sagap I. Serum procalcitonin predicts anastomotic leaks in colorectal surgery. Asian Pac J Cancer Prev 2017;18:1821-5. 